Article

\title{
Behind Subcontractor Risk: A Multiple Case Study Analysis of Mining and Natural Resources Fatalities
}

\author{
Charan Teja Valluru* $*$, Andrew Rae $\mathbb{D}^{-}$and Sidney Dekker \\ Safety Science Innovation Laboratory, School of Humanities, Languages and Social Sciences, Griffith University, \\ Nathan, QLD 4111, Australia; d.rae@griffith.edu.au (A.R.); s.dekker@griffith.edu.au (S.D.) \\ * Correspondence: charan.valluru@griffithuni.edu.au
}

Received: 12 June 2020; Accepted: 26 August 2020; Published: 1 September 2020

\begin{abstract}
Subcontractors have always been linked to higher risk by the industry and academia. However, not much work exists in establishing the reasons behind this relationship. Much of the existing work, either categorise subcontractors under a theoretical label of work to apply the drawbacks of the label to them, or directly enter problem-solving mode. This study focusses on taking the perspective of subcontractors and explores ways in which this viewpoint interacts with safety systems and processes. This study applies a case study methodology to this problem. It examines a total of six cases reflecting six closed single subcontractor fatality accident investigation reports from the year 2004 to 2014 obtained from the Department of Natural Resources and Mines (DNRM) Queensland. These cases are then thematically analysed by employing subcontractor theory to identify themes to categorise the links between higher risk and subcontractors. The themes identified match two pre-existing categories (Institutional safety mechanisms do not cope with variability introduced by subcontractors; expertise in work does not translate to expertise in safety) and two new categories (communication does not flow to the subcontractor from the layers above them; safety work is viewed differently by subcontractor staff when compared to principal contractor's/operators') of subcontractor risk. This study aims to serve as a starting point for further research in understanding the subcontractor safety situation by putting things into the subcontractor's perspective.
\end{abstract}

Keywords: subcontractors; mining; safety work; case studies

\section{Introduction}

It has been suspected, for some time, that subcontractors are at higher risk of being harmed at work than other workers. However, this has not prevented the increase in extent of work subcontracted across high-risk industries, leading to substantial interest from the academia and the industry in this problem [1,2].

\subsection{Reasons for Subcontractor Risk}

What is it about subcontractors that might put them at higher risk? There have been various approaches that researchers have taken in answering this question. The more theoretical approach targets the non-permanent nature of subcontractor employment relationships. Social scientists who have taken this route focus on understanding the experiences of the workforce, rather than the system they work within. Their approach makes use of labels such as temporary work [3], precarious work [4-6] and contingent work [7,8], which have been shown to be linked to an increase in risk [9-12] in the work performed by subcontractors.

Another factor in understanding why subcontractors are at a higher risk is by taking a systemic approach and considering the issue at an organisational level. Some of the risks that subcontractors face are attributed to the small and medium enterprise (SMEs) structure as most subcontracting firms 
are small or medium in size $[13,14]$. The reasons include inherited issues such as financial and time pressures and a lack of Occupational Health and Safety (OHS) knowledge as reasons behind the risk that subcontractors working in small and medium firms face $[13,15,16]$.

Some of the research has focussed on an even broader overview that connects more reasons to the risks faced by subcontractors, which is based on the interorganisational complexity when considering subcontracting organisations as parts of large complex systems [17,18]. Factors, such as loss of communication $[19,20]$, a lack of clarity in the OHS responsibility for subcontractor employees [15,21], failure of institutional safety mechanisms [1], competency issues [22,23] and unfamiliarity with work atmosphere [24] are some of the reasons that arise from this complexity.

From a regulatory perspective, Australia's Harmonised Work Health and Safety Acts and the Work Health and Safety Acts both impose the requirement to consult, cooperate and coordinate their activities to ensure that the OHS necessities of the subcontractor employees are met on both the subcontractor and the principal contractor managements [25]. However, such consultative processes offered by regulations cannot always be made use of by casual and short term subcontractors [26]. In Australia, smaller subcontractors have found it difficult to implement the necessary compliance due to the implementation costs, language and educational barriers and a fear of change [15].

\subsection{Approaches to Reduce Subcontractor Risk}

The heavy reliance of principal contractors on subcontractors is more evident in industries, such as construction and mining, with the former depending on subcontractors for up to $90 \%$ of the work by value [15]. The bodies in charge of business functions, such as mine operators and principal contractors apply various means to safeguard the wider safety performance from subcontractor risk $[27,28]$.

Existing means of controlling this risk are mechanical in nature. Some management and business researchers who believe that organisations would need to treat their subcontractor workforce in a certain way have tackled this as a management problem calling it (sub)contractor management [29-31]. An example of this approach, as witnessed in the field of operations research is to focus on the procurement stage and implement a subcontractor selection process through various models of pre-qualification [31,32] of the firms involved in subcontracting [33,34]. This example showcases an approach that directly attempts to address the problem, perhaps at the expense of more in-depth analysis of the causes of the problem. Partnerships and alliances are seen as an a substitute to the traditional bidding process between operators/principal contractors and subcontractors $[35,36]$.

The overview of both the risks and the control approaches suggests missing links that connect the experiences of the workforce to the solutions. This study aims to take a step in this direction by answering the important question of how the lived reality of subcontractor work interacts with safety management systems and processes. It takes on a qualitative methodology and utilises fatality accident investigation reports in the form of case studies to identify the reasons behind subcontractor risk. It then presents the results of the thematic analysis on these case studies, and later these findings are discussed.

\section{Materials and Methods}

This study takes a qualitative methods approach, which helps obtain a deeper understanding, using real-life perspectives, in greater detail [37]. It employs a multiple case study-based methodology, which is known to answer the 'how' and 'why' questions [38]. Accident reports have previously been used as case studies to identify root causes [39,40]. It presents and analyses a series of case studies, where each case is a mining-related subcontractor fatality in Queensland, Australia, between 2004 and 2014.

The original investigators analysed all the incident reports used as part of this study based on the same framework. This was done irrespective of the category of the person/s deceased (Operator/Principal Contractor employee, subcontractor employee or a visitor). However, given what we now know about 
the variations involved in being a subcontractor employee, this study applies a subcontractor lens to re-examine the subcontractor fatality incident reports as detailed below.

The case studies were analysed thematically based on an abductive analysis process [41] and followed the steps laid out to perform a thematic analysis by [42]. This matching process looks for features of the case studies that match existing theoretical discourse about subcontractor work. The directing and redirecting process looks for elements of the case studies linked to the subcontractor nature of the work, but which do not fit neatly into existing theory. The first stage involved data familiarisation, where the authors completed multiple readings of the case studies (accident investigation reports) and ideas were noted. A preliminary summary of the noted ideas followed, to populate initial tentative themes. A review of the themes was then conducted in an iterative process until a clear list of themes were obtained that provided a detailed picture of the case studies being analysed. These themes were then categorised into broader categories based on previous literature. The final step, then involved a formal write-up and presented under the 'analysis' section.

The case studies for this paper were collected in the form of incident investigation reports from the Department of Natural Resources and Mines (DNRM) of Queensland. Upon receiving permission from DNRM to view the fatality incident reports from incidents, the authors spent three months going through these reports under the supervision of a senior mines' inspector.

Reports were included within this study if:

- $\quad$ The incident occurred between 2004 and 2014;

- The incident involved at least one fatality;

- At least one victim was a subcontractor employee; and

- There was a completed investigation by DNRM with the full report available

A total of 25 incidents resulting in 25 fatalities and 3 injuries occurred in mines and quarries located in Queensland between 2004 and 2014 as per DNRM data. After application of the second filtering rule, the number still stood at 25 fatalities and 3 injuries. Given the paper's focus on subcontractors, only the 11 incidents that had resulted in the deaths of subcontractor employees were selected. After excluding the reports that were not investigated by DNRM (as the incidents occurred outside their jurisdiction) and/or had an incomplete investigation, 6 reports remained. These 6 were chosen as the case studies for this research. Figure 1 shows the filtration process.

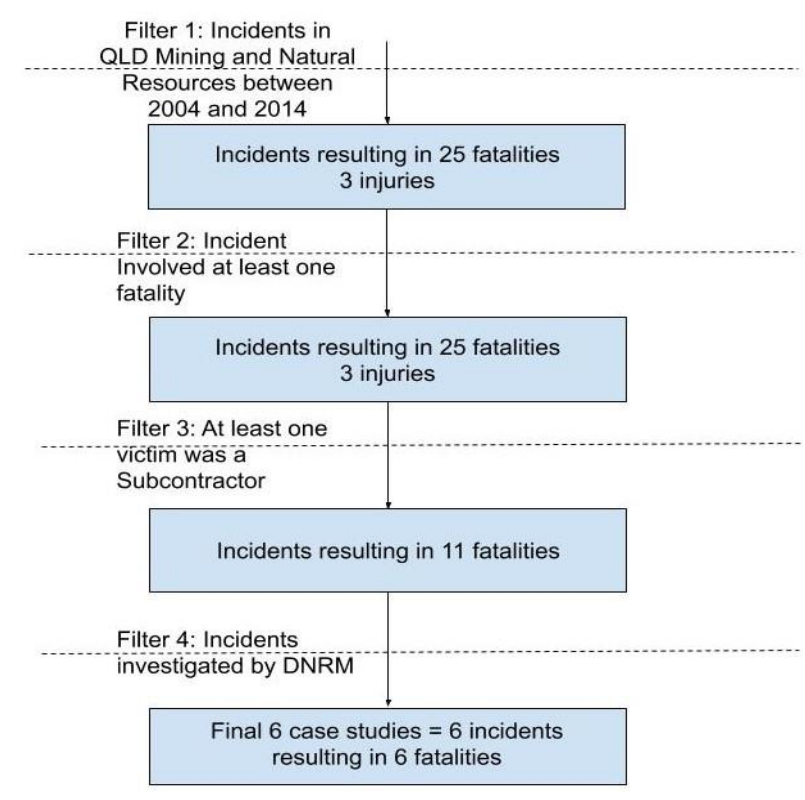

Figure 1. Incident selection process. 
Apart from an established timeline of events leading to the incident, all six reports included Incident Cause Analysis Method (ICAM), as the method of analysis of the factors identified. ICAM is an accident investigation tool that is used to identify the deficiencies and failed defenses at the organizational level followed by recommendations to rectify these gaps [43].

As the incident reports were directly obtained from DNRM, no identifiable information has been used in representing these case studies to protect the privacy of the individuals and organisations involved.

\subsection{Theories Related to the Analysis}

The matching process applied the following theories.

\subsubsection{Institutional Safety Mechanisms}

Institutional safety mechanisms refer to the various methods applied to help ensure the safety of employees on site. On a mine site, these mechanisms would commonly be part of the mine's Safety Management System (SMS). Mine Operators/Principal Contractors have their own employees working under this SMS. Subcontractors hired to work on these sites would generally, either follow the mine's SMS or use an SMS that has been pre-approved by the mine Operators/Principal Contractors. Studies indicate that these institutional safety mechanisms often do not function as intended when it comes to protecting subcontractors [1]. The variability of subcontractors in terms of operating simultaneously or sequentially on various sites under various Principal contractors makes it challenging to manage and maintain an SMS [44]. Certain elements of the SMS have been further explored concerning subcontractors. Training and induction programs, for example, when improperly administered, were also found to hurt subcontractor safety [45]. Another example, at an even more basic level, is Personal Protective Equipment (PPE). This equipment is required to assist employees remain physically safe. However, some studies suggest that subcontractors are found to use inferior quality of PPE [46] or that PPE is less available to them [47].

\subsubsection{Labels of Work}

There are multiple labels of work under which subcontracting has been nested throughout literature, which focus on the non-permanent nature of work. The more widely used being precarious work, contingent work and temporary work.

Precarious work is characterised with a component of insecurity with regards to the job and income involved. It encompasses under its forms of work arrangements, such as casual or fixed-term and temporary employment that reflect these insecurities [48]. While there are opinions on what types of work qualify as precarious [49], not all subcontracting work can be categorised under this label. Self-employed subcontractors [48] and workers that are hired on a casual/fixed rate by subcontracting firms do qualify.

While often used in similar contexts to precarious work, contingent work refers mainly to work performed by employees who do not have a long-term contracts, and their minimum work hours may vary [7]. Therefore work performed by sub(contract) employees with long-term employment (based on demand for their services or if the firm hiring them is in business) or self-employed specialists, do not fit this label [50].

'Temporary work' as a label fits workers who are as the name suggests are 'temporary'. Therefore, it fits workers hired by labour-hire and temporary agencies and subcontractors [3,51]. On the other hand, (sub)contracting work differs from temporary work as the former often have supervision on sites when compared to the latter, which does not [3].

There is some work available that connects these labels to adverse safety outcomes. Of these work types, precarious work provides a model, known as the PDR model that captures the safety outcomes for precariously employed workers in to 'Pressures', 'Disorganisation' and 'Regulatory failure' [8]. We have discussed the model's relevance to the subcontractor safety problem in our previous paper [1]. 


\subsubsection{Transfer of Information between Layers of the Contracting System}

Transfer of information between layers involved in a project must be effective and complete. However, subcontractors are generally positioned at the other end of the contracting structure [52], making it difficult for them to receive any firsthand information from the top layers. Most information they collect often passes through layers in between them and the client or in some cases, the regulator. This filtration of information is especially true in the case of small and medium subcontractors, who make up a majority of the subcontracting sector. In their article on understanding the obstacles of implementing health and safety reforms, [15] submit that, in the case of small and mid-sized subcontracting firms, the filtration of regulatory information between themselves and regulatory authority through Principal Contractors could lead to ineffective implementation of regulations. Another means of the transfer of information, significant in multi-subcontractor sites is between the subcontractors involved. In a study conducted in the domestic housing sector, a lack of information transfer between subcontractors increased the chances of unsuspected hazards being left on-site before the next subcontractor arrived on-site [53].

\section{Case Studies}

The following are descriptions of the incidents in chronological order.

\subsection{Case Study 1}

A truck driver was fatally injured on a mine site after one of his truck's tyres burst.

The driver was employed by a mining services firm that had been contracted by the mine operator to haul coal. The owner of the mining services firm had started the business with one truck, and at the time of the incident was running approximately thirty trucks on multiple sites for multiple mine operators. While the mining services firm was small, the firm had been operating under the mine operators' or principal contractors' Safety Management Systems. The growth in the organisation had required several changes, including the adoption of a Safety Management System designed by an external consultant, and appointment of site manager and general manager roles.

At the time of the incident, the truck driver had been employed in his current role for nearly 21 months. This role involved hauling coal from the site on a truck and performing minor truck maintenance tasks such as changing tyres. On the day of the incident, he was handed-over a truck from a nightshift driver. The nightshift driver had conducted safety inspections of the truck and believed that it was safe. The incoming driver informed his supervisor that he wanted to change the tyre as he felt it was 'doughy' (low on pressure). The supervisor, who was experienced in the driving work but had limited experience in changing tyres, approved the task.

Changing mine truck tyres is a hazardous task because of the high pressures involved-burst tyres can release catastrophic levels of energy. The previous year, the regulator had conducted an audit of wheel and rim safety which had resulted in updated Standard Operating Procedures (SOP). The mine operator adopted the new SOP but did not communicate it to the mining services firm.

A tyre fitter was employed part-time at the mining services firm's tyre changing station located within the workshop. However, it was the responsibility of the truck driver to remove the tyre and replace it with a functional one. The damaged tyre would be later looked at by the tyre fitter. Hence, after informing the tyre fitter his intentions, the truck driver started working on the wheel. There was an explosion. Two of his colleagues (including the tyre fitter) who were working in the next bay came running to discover the truck driver on the floor with a severe head injury. He was found still breathing, but he died shortly before he could be airlifted by medical evacuation aircraft.

The official investigation report noted the following factors as causally relevant to the accident: No training on the SOP for replacing multi-piece rims; did not communicate/enforce SOPs related to the outcome of inspector's audit, tyre deflation to $30 \mathrm{psi}$, rim register and rim to be removed after 
3 years or 15,000 h of service; employees of the subcontractor were not trained in the relevant national competencies for wheel/rim changing, and the procedure for inspecting rims was not enforced.

\subsection{Case Study 2}

A loader operator was fatally wounded after he was crushed by the cab of a front-end loader he was driving.

The loader operator (single person subcontractor) was brought in by the mine operator to complete bulk sampling operations on a site. The subcontractor hired a loader but was unfamiliar with the specific loader supplied and was not known even to have experience with that type of loader. The operator drove the loader back and forth between the main office and the "pad" (on which the collected samples were being dumped). He completed two of these trips successfully and was on his third trip to the pad when the engine stopped functioning. He realised that the loader had no effective reverse or park braking and so steered it up to the bank of the road to bring it to a halt. After he exited the vehicle, it tipped and fell on him. He was found crushed under the cabin of the loader.

A mechanical inspection of the loader revealed several issues. A 'wire similar to a fencing wire' was used for wiring up the cab window by the loader operator. The horn was not functioning. The loader was found to have no effective reverse breaking as it lacked enough Nitrogen gas pressure in the accumulators and the parking brake could not be used in emergencies as most of its parts were missing.

The deceased was not known to have previous experience with this type of loader. The mining operator's office had no record of his competency certificate. He had completed an induction before commencing work and had stated 'wearing a seatbelt' to be the condition of operation, but he was not wearing his seatbelt when operating. The site safety management plan, which covers all the employees working on the site, did not include plant operators. The mine operator's Safety Management System (SMS) was continually being upgraded, and various components of the same were found in isolation to each other.

\subsection{Case Study 3}

A subcontractor employee was fatally crushed between the hopper doors of a crusher he was repairing at a quarry.

The employee had previously repaired a hopper on a different quarry site, but this particular hopper was believed to be of a different design. He managed to remove the top pin that controls the lowering and raising of the ram using a chisel and hammer. This resulted in the hopper door swinging down, hitting his upper body.

The employee involved in the fatality was hired by the subcontracting firm as a school-based apprentice boilermaker. He was accompanied by another employee to help conduct the hopper repair. Both employees had only completed site orientations and not inductions as was common at this site for short term contractors. The second subcontractor employee was on his first day at the quarry, and neither subcontract had any experience in hoppers nor aware that there were standing instructions that the hopper doors should be removed before any maintenance activity. An operating manual for the machine was not available on this site but was at the main office of the operator. They were informed of the location of the necessary tools and equipment by an operator employee.

The site safety executive, while providing the subcontractors with initial instructions to complete the repairs, did not supervise them. He was aware of the subcontractor as he had previously worked with him and had proved to be competent. He also did not complete any risk assessment before leaving.

While there were daily safety meetings held on-site, written risk assessments were not part of their procedures. 


\subsection{Case Study 4}

When completing a water route, a subcontractor crashed his truck through a bund wall killing him in the process.

The employee involved in the incident held nearly 33 years of experience in driving heavy vehicles by the time a company employed him as a casual Truck Operator. In the same year, he was subcontracted as a Machinery Operator and was responsible for operating a water truck on the quarry. His job required him to water the roads on the site to help suppress the dust. He was believed to have completed his induction for this site, but the necessary documentation to prove this was not found.

Ten minutes before the incident, an employee of the quarry spoke to the subcontractor employee to ensure that it was the last trip. During this conversation, the subcontractor told the regular employee that he was going to flood the roads to get rid of the loose dust particles as other trucks were skidding due to them.

Once done tipping the water at the top of the road, the driver proceeded to drive downwards and failed to negotiate a left-hand turn at a ' $\mathrm{T}$ ' intersection. There was no evidence to indicate that the brakes were applied. It was also discovered that he was not wearing his seatbelt.

Records indicated that the decedent had failed to note that he had completed daily services and pre-start checks which he was required to do. The truck's brakes were not adjusted according to the standards. The principal contractor lacked a formal contractor management plan, and the subcontractor firm was not aware of the principal contractor's safety management system.

\subsection{Case Study 5}

A sump pump swung down, striking a subcontractor employee who was hosing the bund area below the hoisted pump injuring him fatally.

The pump in question had failed and needed repairs. Two teams of subcontractors both belonging to different subcontracting firms were contacted to perform two separate but connected tasks. One team (SC1) was responsible for removing and repairing the pump, while the other (SC2) was to vacuum the weak acid from the bund to enable its removal.

Both teams obtained the necessary 'permit to work' forms to complete the tasks from different managers on the site. SC2, whose initial job was to remove the weak acid and sludge from the bund and transport it in a truck from the site, was informed of a change in their task. It was now to pump the material removed from the bund into the adjacent bund and not the truck that it had now parked next to the first bund for convenience. SC1, on the other hand, had to undertake a complex vertical hoist of the pump from the bund, after realising that there wasn't enough headspace required for crane access. Alternative means of removing the pump were not considered even when the supervisor responsible was aware of them.

SC2 allocated the task of pumping the material from under the now hoisted sump pump to one of its employees. This employee had consumed methamphetamine before commencing the assignment. As the process involved working close to the pump, the SC2 team decided to wait for SC1 to complete its task. However, the supervisor of SC1 told the SC2 employees that they could work around them. Members from the SC1 team were not allocated tasks based on their competencies and were unaware of the requirement of a separate rigger. The applicable safety management system requirements were not known or understood by them.

The SC1 supervisor did not consider his training which suggested using a bow shackle for such hoists. Instead, he instructed his employee to sling the load and retrieve a chain block. The employees followed these instructions, leading to the failure of the safety catch under the pressure of the sling attached. This failure resulted in the pump swinging down onto the SC2 employee working directly under it injuring him fatally him in the process. 


\subsection{Case Study 6}

An underground mine worker was struck by a rib spall and fatally injured as he was installing grout tubes into drilled holes.

A two-member team (employee E1 and supervisor E2) of a subcontracting organisation were allotted to work night shifts at a mine site. E1 attended the pre-start on the site, but E2 did not. E1 was assigned the task of placing tubing in the holes and sealing them in place with grout, while E2 was assigned to drilling. The location allocated was previously used for storage and filled to the roof with debris resulting in severe corrosion to the structure leading to a spall.

The area where the rib failure occurred, causing the fatality, was not supported as two rib bolts were missing. Neither the mapping company that surveyed the region nor the controllers noticed this failure. Since E2 did not attend the pre-start, he was unable to inform the controllers or mine operator about the location of E1 and himself.

The first inspection performed the night following the incident could not be completed as there was confusion between the mining officials about where and how the subcontractor employees were deployed. The mine planning system contained information regarding the activities of the subcontracting firm in question, but this system was not updated. An engineering control that was mentioned in the contract to help protect employees working in this area was not implemented. A statutory inspection, which could have identified this issue, was not conducted either.

\section{Analysis}

\subsection{Institutional Safety Mechanisms Do Not Cope with Variability Introduced by Subcontractors}

Mining organisations have a number of standardised institutional protections to keep employees safe [54]. These include inductions, pre-starts/toolbox talks, well-maintained equipment and tools and management systems. In terms of subcontractor employees, some or all of the safety systems seem to, either not function as planned, or fail altogether, leaving them vulnerable to risk. The reasons behind failure mostly stem from the variations involved in being a subcontractor and the nature of work they perform as evident. This is particularly the case for subcontractors engaged for short durations [26] as witnessed in three of the cases reviewed. The incidents are limited when subcontractors work under the same principal contractor for a longer duration or on multiple projects. In the latter case, the familiarity with these institutional safety mechanisms of the subcontractor employees increases, leading to the less chance of failure. However, the systems could still fail in the case of newer subcontractor employees, irrespective of the length of relationship with the principal contractor. This failure of systems, as seen in the cases reviewed, is presented below.

\subsubsection{Variations in Time Spent on Site}

Subcontractors often perform small tasks, and this leads to them being on-site for a short period of time just enough to complete the allocated task. Operators/Principal Contractors in three of the reviewed cases used this as a reason not to subject these employees to the otherwise required procedures.

In case, 2 for example, the site safety plan of the principal contractor did not include operators of vehicles related to the sample collection process (such as the deceased employee) as they were only hired to perform tasks that lasted a short period of time. Similarly, in case 3, the two subcontractor employees were only asked to complete site induction, and not the complete induction as it was believed that they would not be on site long and leave after the repairs to the hopper were completed. In case 5, the workers assigned to the task were found not to have completed both the site's and the principal contractor's inductions. The employee, who was later fatally injured, only had little experience in the site conditions due to the lack of induction. The principal contractor was found not to have implemented their contractor management plan effectively. This reason as well as the nature and duration of the task of vacuuming sludge led to the subcontractor team not being inducted. 


\subsubsection{Multiple Jobs on Multiple Sites}

Subcontractors pick up multiple jobs on multiple sites. This practice leads to their employees having to complete several inductions and pre-starts every time they get on to a new site. While inductions are essential safety mechanisms that organisations rely on [55], subcontractor employees gradually lose interest as they repeat these inductions and start to treat every new induction/pre-start as 'just another', as found in two of the cases reviewed.

This disinterest and lack of attention in site inductions could prove counterproductive. In two of the mobile plant-related cases reviewed here, the investigators discovered that the deceased employees were not wearing their seatbelts, even though the inductions they underwent stressed on their importance. In fact, in case 2 , the deceased subcontractor employee had even explicitly noted (as part of his induction assessment) seatbelts as necessary to perform his job. This evidence reinforces the idea that the inductions were never taken seriously/not paid attention to.

Site pre-starts and toolbox talks are places where vital site and task-related information gets passed on [56,57]. They also contain site-level information on the conditions and the procedures that are required to be followed when commencing work on site. In the case of the subcontractor employees, two things generally happen. Either they are not made part of these activities, or their participation is not monitored or made mandatory. In case 6, since the supervisor (E2) did not attend the pre-start, the employee (E1) did. During this pre-start, it was mentioned that a SLAM (Stop, Look, Assess, Manage) procedure would be needed to be completed before every shift as part of the site's SMS. E1 was now aware of the SLAM process, and E2 was not. At the beginning of their shift, E1 completed the SLAM procedure for his supervisor's (E2) task but not on his own. While the ability of E2 in noticing the rib conditions as a hazard had he completed SLAM for his own task is debatable, there was a procedure in place which was not followed as E2 did not attend the pre-start and hence was unable to complete it. The missing information from the pre-start also resulted in E2's failure to communicate his and E1's location to the mine operators following the incident.

\subsubsection{Different Rules at Different Times on Different Sites}

The management of safety in large sites is achieved by employing a Safety Management System (SMS). An SMS as defined by the International Civil Aviation Organisation (ICAO) is "a systematic approach to managing safety, including the necessary organisational structures, accountabilities, policies and procedures" [58]. It forms an integral part of an organisation's management plan and is intended to help employees stay safe [59] and is applied similarly to all Operator/Principal contractor and subcontractor employees working on the same site [60].

As a rule of thumb in Australia, subcontracting companies lacking their own SMS would need to follow the SMS of the principal contractor [61]. For those that have their own SMS, it would be necessary to be verified and approved by the principal contractor under which they are working to be used on their sites. Either way, this ensures that every subcontractor on site is functioning under an SMS. There are issues in both scenarios that could prove counterproductive [61].

When a subcontractor functions under the SMS of a Principal contractor, the issue of multiple jobs on multiple sites comes in to play again. As suggested in the previous section, it is not uncommon for subcontractors to undertake multiple jobs on multiple sites for multiple principal contractors, either simultaneously or consecutively. This practice leads to employees of these subcontractors needing to adapt to a new SMS every time they are under a new principal contractor on a new/different site. This can lead to confusion amongst the employees and could also lead to sometimes losing track of the SMS they are functioning under, as observed in two of the six cases reviewed. In case 3, the SMS of the Operator was being upgraded, so pieces of it were found in various locations. In some version of this SMS that was conveyed to the subcontractors on site, it was found that the site management plan never included the plant operators on site of which the subcontractor was a member. On the other hand, in case 4, the subcontractor organisation was not even aware of the principal contractor's SMS, and there were no indications of any issues raised as to this lack of awareness. 
The alternative approach is for subcontractors to use their own SMS as compared to using the SMS of the operator/principal contractor [61]. Conversely, there are some concerns here as well. Consider case 1, for example. The subcontracting company, in this event, had previously always relied on the Operator/Principal Contractor SMS of the worksite. However, the principal contractor on the site, where the incident occurred, suggested it was time for the subcontractor to have their own SMS given the pace at which the subcontractor was growing. The subcontractor management hired an outside 'expert' to compile an SMS to meet this requirement. Draft versions of this new SMS were rejected multiple times by the Site Safety Executive (SSE) of the site as being incomplete and inefficient. In place of the new still under-design SMS, the subcontractor was using the previous subcontractor's SMS that they had replaced on site. This practice was evident from the previous subcontractor's labels found on a current Standard Work Procedure (SWP) document recovered after the incident by the mining inspectorate. This example highlights the issues that subcontractors face when required to have their own SMS. As they lack the necessary management skills to design and deploy their own SMS, subcontractors choose to, either adopt a different subcontractor's SMS that is not tailormade to suit their organisation, or depend on outside 'experts' who have no/limited knowledge of the subcontractor's area of specialisation to help them develop one. The operator/principal contractor on whose site the subcontractor proposes to perform work verifies this newly built SMS. Since the operator/principal contractor hired the subcontractor for their expertise in completing the task, the rationale behind the former verifying something that is clearly outside their domain is not clear.

\subsection{Expertise in Work Does Not Translate to Expertise in Safety}

Expertise plays an important role in the process of subcontracting. In all six cases detailed in this study, the subcontractors were hired to perform specialised tasks in which they were considered to be experts. The question then becomes why these experts were not able to translate their expertise in work into better safety. As detailed below, it will become evident that in at least some of the cases, the expertise was never questioned. The operator/principal contractor management often took the subcontractor's word for it and failed to exercise any checks of the actual documentation that would prove their expertise. This was due to the fact that these jobs were of shorter duration and hence not given the importance they would have received were they longer, or the expected risks involved in these jobs were not considered to be high enough to warrant a check of the qualifications. Either way, the frequency of expertise playing a role in one way or the other in leading to the incident is high. We looked at the various reasons behind this and found the following.

\subsubsection{Financial Constraints, Multitasking and Expertise}

Given the size of some of these organisations and the nature of contracts they are involved in, financial constraints are not uncommon [62,63]. Previous research does suggest that subcontractors apply various cost-cutting measures in various areas to meet needs [15,64]. The same constraints, coupled with the small size of these firms, leads to employees performing multiple tasks outside their expertise in areas that they are never fully prepared to perform $[65,66]$.

In case 5 , it was found that SC1 was only subsidising half the amount necessary for their employees to get the necessary training. This caused many employees to opt out of the specialised training and were depended on those trained to make their decisions. In case 1, the organisation decided to hire a tyre fitter part-time who was shared between sites. This had created a need for the employees to remove the tyres themselves rather than wait for the fitter. It was also found that a number of subcontractor employees were not trained in the principal contractor's procedures.

Case 1 is another example where the concept of multitasking comes into play and reflects poorly on expertise. The supervisors working at the time had all started as drivers and had been promoted through the ranks to their current roles based on their experience and expertise. However, they were expected to multitask as well. For example, their general responsibilities, included but were not limited to, giving permission to the employees to perform tasks, relieving drivers when they needed 
a break, monitoring their work practices and sometimes perform regular driver duties. In the case of the deceased driver, his immediate supervisor had given him permission to change the tyre on a multi-piece rim, but he had never changed a similar rim in his work experience. The report later also argues that he was not competent to suggest any safety means to the employee.

\subsubsection{General vs. Site-Specific Expertise}

In two of the cases reviewed, where subcontractors stated having previous experience to perform work, may refer to general expertise and not site-specific or work specific.

For example, we found in the coroner's report on case 1 that, while it was true that the subcontracting firm had experience in the past, most came from roads and not mining in the business of transportation. The report argues that, while the organisation had been running a lot of trucks on mine sites, the drivers themselves might not have been entirely aware of the necessary conditions that applied when driving on a mine site. Similarly, in case 4 , the deceased driver was known to have 33 years of experience in the driving of heavy vehicles. Whether this experience involved him driving on quarry sites is unknown. Given he was found without his seat belt on and failed to negotiate a left-hand turn on a ' $\mathrm{T}$ ' junction, one can assume that he had no experience in driving in these conditions.

\subsubsection{Verifying Expertise}

While different employers have different means of verifying said expertise, there are two primary means generally underuse. The first means is to verify the qualifications of the employees through their competency certificates. The second means is to check their experience through the references provided. We explain below how the two general means of verifying expertise of subcontractors, as evidenced in two of the cases we reviewed.

The most common means as declared above is to rely on competency certificates of the employees provided through the subcontracting firms. Sometimes, for tasks of a smaller duration, these competencies go unverified as in case 2, where the subcontractor hired to complete the sample collection in had claimed experience with similar loaders in the past. However, there was no evidence of records with the mine operator that had hired his services that could prove this specialist vehicle driving competency. Post incident, a mechanical inspection of the vehicle was conducted by the inspectorate. It noted several shortcomings on the vehicle but identified alternative functional brakes to stop the vehicle which an operator with experience in handling this type of loader should have been familiar with. Given that the deceased had failed to apply these brakes leads to question his actual self-claimed competency in operating this specialist vehicle. Expertise in all areas of multitasking is expected but not verified. Another example that illustrates a different outcome of the same issue is from case 1, where the driver was expected to change tyres on multi-piece rims, but was not provided with any related training, as evident from his training record at that mine site.

The other means for verifying subcontractor expertise falls under the category of previous experience. Experience in performing a task generally assures employers of the employee's ability to perform the same job in the desired safe manner. However, in the case of the subcontractors verifying this experience could become pivotal. We explain this further through case 3. The subcontractor employee removed the top pin using a chisel and hammer leading to the hopper door to swing down fatally injuring him in the process. This employee had claimed previous experience and in this case of having worked with a 'similar' machine. The principal contractor did not clearly verify his expertise. In fact, the subcontractor never provided any training documents to support his claim of experience. However, he had previous work experience under the Site Senior Executive (SSE) who was currently in charge and found 'competent', and hence, hired to perform the repair. In trusting the subcontractor's expertise and experience, the SSE did not supervise his work and did not provide any instructions on ways to implement the task. He only provided him with the sequence of steps to be followed and did 
not conduct a formal risk assessment. However, it was a mobile crusher with a different design to the one he had previously worked with.

\subsection{Communication Does Not Flow to the Subcontractor from the Layers above Them}

Communication of information needs to occur at all levels on complex sites to ensure safe operations. Information on site-specific conditions, location of tools and equipment, points of contact in case of an emergency, etc., are all important when working on such sites. Given the subcontractors are generally at the bottom of the chain, the communication of important issues and updates hardly reaches them at times. In addition, some of the tasks have relatively shorter duration, and not needing much communication between the subcontractor employee and the operator/principal contractor, proves a hindrance for the former to have the required information to perform their jobs safely. This also holds true for the communication from the operator/principal contractor, or even between two subcontracting firms, who might be working on the same site as witnessed in two of the cases reviewed. This disruption in communication seems to occur more frequently on larger sites with a large number of players, when compared to smaller fewer complex sites. We outlined below the cases reviewed that demonstrate communication breakdowns.

\subsubsection{Filtration of Regulatory Information}

Information regarding all issues first reaches the operator/principal contractor, as they control each site. It is operator/principal contractor's responsibility to pass on this information to all their employees and the subcontractors' employees on site, as necessary. However, this does not necessarily happen at all times, as seen in case 1 presented below. Regulatory information is often filtered before it can reach the subcontractors [15].

The incident investigation report on case 1 suggests that the subcontractor employee fatality occurred as a result of a sudden release of stored energy from the tyre that he was trying to replace. A similar incident had happened at a Queensland mine just the previous year, causing a fatality. After investigating the incident, the mining inspectorate sent out information on the findings and changes necessary to the work procedures to all mine sites. In fact, the inspectorate had completed an audit of wheels and rims at the mine site almost a year ago. In this audit, it was recommended that changes to the existing Standard Operating Procedures (SOPs) should be made regarding the replacement of tyres. This vital information passed on from the inspectorate concerning the changing of tyres on multi-piece rims was not communicated to the subcontracting firm even though the firm was functioning vehicles with said rims. The subcontractor was still operating under versions of the SOPs that were all found to be at least two years old. Hence, the information on multi-piece rims never reached the subcontractor and as a result, did not make it to the employee who was replacing the tyre.

\subsubsection{Layers of Complexity}

When a subcontractor is performing under the operator's/principal contractor's SMS, information regarding procedures and tasks, as per the SMS, needs to be passed on to the subcontractor from the operator/principal contractor. But given the complexity of some of the sites in which subcontractors operate (there are usually multiple subcontractors working at the same time) the information does not reach the subcontractors. Communication between these teams, when working on the same task, is essential, as shown below in three of the cases analysed.

In case 3 , the requirement to complete risk management was never communicated by the principal contractor to the subcontractor. The operating manual for the hopper that was to be repaired was not made available on site. Therefore, repairs depended completely on the experience of the subcontractor. In case 2 , the SMS of the operator was being regularly updated and was not complete. This was passed to the subcontractor involved in some form.

Case 5 serves as another excellent example of the importance of site communication at all levels. The principal contractor did not conduct any regular meetings with SC1 and SC2, suggesting that 
there was a lack of information transfer between them. The employees of SC2 were not aware of the SMS of the principal contractor. Also, there was no proper communications between both the subcontracting teams working on the same site. SC1 could not place the crane they needed to hoist the pump in the desired location as SC2 required the same spot to park their trucks that were to carry the pumped sludge. This important decision was never discussed between the two subcontractors. Finally, after initially suggesting the team (SC2) not to go in until after the other subcontractor team (SC1) is done, the supervisor of SC1 decided to let the SC2 team go ahead asking them to 'workaround' the hoist they had raised lifting the pump.

\subsection{Safety Work Is Viewed Differently by Subcontractor Staff When Compared to Principal Contractors'/Operators'}

For the purpose of this paper, safety work is defined as the effort that goes into ensuring that work is performed safely. This includes planning, paperwork, and the means in place to mitigate any unwanted outcomes for the employees involved. While this view does not change with both Operator/Principal Contractor employees and Subcontractor employees, the importance given to them does to some degree. Two views of what these might look like to both parties have been presented below as abductively derived from three of the case studies for each view.

\subsubsection{Core Tasks and Non-Core Tasks}

For the purpose of this paper, core tasks refer to the tasks that need to be completed in order to complete the job at hand, and refer to the actual work, which is the reason behind their employment. Whereas non-core work or discretionary work refers to the tasks that need to be completed, but without whose completion, the core task is still considered complete. These would include maintenance of tools and equipment, filling in paperwork, attending pre-starts and other discretionary tasks.

For Operator/Principal Contractor employees' core and non-core tasks would both remain equally important and completing both are seen to be necessary to log the job complete. This would also mean that if a non-core task is not complete, the former can request for an extension of the deadline to do so. However, this might not be the case $\mathrm{f}$ or subcontractor employees. While completing both core and non-core tasks are necessary, the actual completion of non-core tasks might not be as mandatory as long as the core tasks are completed. The Operator/Principal Contractor might not inspect means used to complete as witnessed in three of the cases reviewed, the non-core tasks by the subcontractor employees as long, as they are completed as an extension in time is generally not possible.

In case 1, for example, the logs of tyres and rims were not maintained as required. In fact, up until after the incident and the inspection by the inspectorate, the inconsistencies and incompleteness of the records were not identified. In case 4 , while driving a replacement truck, the subcontractor employee who was later fatally injured did not complete any log entries on the condition of the truck. He did not consider this to be part of his core work. In case 6, the employee could start core work without completing non-core work, such as not attending a pre-start which was later found to contain important site-specific information and could have probably helped save the other employee.

\subsubsection{Short Term and Long-Term Goals}

For the purpose of this paper, short term goals are defined as completing the task at hand. Long-term goals refer to the incentives, such as promotions and bonuses, provided in the long-term for having met their short-term goals.

In terms of Operator/Principal Contractor employees versus Subcontractor employees, the definitions change in terms of their perception, while remaining the same for both goals. For the former, who would be working in full-time capacities, short term goals would be perceived as the main work on their everyday task at hand, and long-term goals would comprise of obtaining an incentive for having completed multiple short-term goals completely. On the other hand, subcontractor employees, depending on the number of projects they are currently working on, would have multiple short-term 
goals to achieve, which in turn would culminate to form their long-term goal. These short-term goals are achieved under tight deadlines implemented in their case. This increases the need for short-term goals to be met as quickly as possible, which has been linked to taking short cuts, in terms of safety [67]. Moreover, as most of them get paid by the hour, long term goals would just remain a sum of short-term goals, and just their completion would be the target.

In case 2, for example, the subcontractor arrived with a loader that had several safety-critical parts missing. He was aware of the condition of the loader but was keener on completing the short-term goal of sample collection and did not consider having a well-maintained loader to be part of his goal. In case 3, neither the unavailability of an instruction manual on site nor the skipping of risk assessment were questioned by the subcontractor employees. They were focussed on their short-term goal of repairing the hopper. Similarly, in case 5, the subcontracting team completing cleaning task when asked to come in and work around a raised pump took it and did not question the scenario as they were planning on completing their short-term goal.

\section{Conclusions}

Safety legislation suggests that mine site operators/principal contractors owe the same duty of care to all workers, regardless of their employment status. However, our analysis shows that, even when subcontractor employees are covered by the same rules and systems as other workers, they experience those systems very differently. This different experience of safety was relevant in all six fatalities. The abductive thematic analysis highlighted four critical areas of concern. The failure of institutional safety mechanisms in keeping up with the variability, introduced by the subcontractor workforce, and the inability of communication to ultimately reach the subcontractors from the top layers of the contracting system, was both inductively arrived at, and could be connected to previous work in the area of subcontractor risk. However, the failure of conversion of expertise in work to expertise in safety and the difference in views of principal contractor staff to subcontractor staff when it came to safety work were results of the abductive analysis.

These results in the form of themes are connected to various pre-existing solutions that are in place to address subcontractor safety. For example, our findings on expertise suggest ways in which expertise of subcontractors fails to be translated into expertise in safety. While, multiple pre-qualification methods for subcontractors do exist to ensure that the subcontractors hired are better qualified to perform the task they are hired for, and in view of our findings, the feasibility of these methods remains under question. Although these methods manage to keep unqualified subcontractors out, the need for some of the qualified subcontractor employees to multitask or the lack site-specific expertise owing to the financial constraints and size of the subcontracting firm, or both, still exist. In this case, a mere acknowledgement that the employees are qualified to do what they were proposed to might not serve the purpose of keeping them safe.

We also found that Safety Management Systems, which are often looked upon as being responsible for the safety of all employees (including subcontractors) do not necessarily cope with the variability introduced by the subcontracting system. Also, the focus of subcontractor employees on core work owing to the time constraints, and their most casual nature of employment leads to partial completion of the requirements of the SMS, which are often seen by them as non-core work. In addition, the filtration of communication from the upper layers was found to affect the loss/misinterpretation of information regarding SMS when it comes to mainly smaller subcontractors at the bottom of the chain.

Finally, the results on differences in views of how safety work is perceived by subcontractor staff, when compared to principal contractor employees, does provide strength to the existing ideas that subcontractors, when under time and financial pressures, cut corners in terms of safety [67]. Time pressure leads to the fixation towards completion of core work as the completion of the task and attaching less importance to any non-core work that does not directly influence the task, leading to the only on-paper end of otherwise necessary safety work, which is now non-core. Similarly, incentives that would form part of a long-term goal for principal contractor employees form part of short-term 
goals for subcontractor employees as many of them are hired on a casual basis and get paid by the hour. This would mean that the amount of effort that goes into short-term goals does not go into long term goals.

The argument here is not that all of these fatalities could be prevented, but if factors, such as the ones presented in this paper were understood well, and built into a feedback loop into the system, the focus may shift on to other factors that are now emerging. For this to occur, an increased focus is necessary from organisations that employ subcontractors in making sure that the factors behind the risks facing subcontractors are identified, understood and analysed using alternative approaches, which can take into consideration the variation brought in by the subcontractor workforce. One means by which this could be accomplished is by considering a renewed focus on qualitative approaches to the problem. For researchers, a direction this could take could be in the form of a comparison study of the subcontractors' issues with those of direct employees of operators or principal contractors would help understand why mechanisms designed to help the former are failing. This would benefit, not just the subcontractors themselves directly, but also provide benefit to the organisations that have now come to rely heavily on this workforce with the changing nature of work.

Author Contributions: Conceptualization, C.T.V.; methodology, C.T.V.; validation, C.T.V. and A.R.; formal analysis, C.T.V.; investigation, C.T.V.; resources, C.T.V. and A.R.; data curation, C.T.V.; writing-original draft preparation, C.T.V.; writing — review and editing, A.R.; visualization, C.T.V.; supervision, S.D. and A.R.; project administration, A.R. All authors have read and agreed to the published version of the manuscript.

Funding: This research received no external funding.

Acknowledgments: The authors would like to thank Maura Thompson and John Kable from the DNRM for their help with the data collection for this paper.

Conflicts of Interest: The authors declare no conflict of interest.

\section{References}

1. Valluru, C.T.; Dekker, S.; Rae, A. How and why do subcontractors experience different safety on high-risk work sites? Cogn. Technol. Work 2017, 19, 785-794. [CrossRef]

2. Gochfeld, M.; Mohr, S. Protecting Contract Workers: Case Study of the US Department of Energy's Nuclear and Chemical Waste Management. Am. J. Public Health 2007, 97, 1607-1613. [CrossRef] [PubMed]

3. Kalleberg, A.L. Nonstandard Employment Relations: Part-time, Temporary and Contract Work. Annu. Rev. Sociol. 2000, 26, 341-365. [CrossRef]

4. Burgess, J.; Campbell, I. The Nature and Dimensions of Precarious Employment in Australia. Labour Ind. A J. Soc. Econ. Relat. Work 1998, 8, 5-21. [CrossRef]

5. Rodgers, J.; Rodgers, J. Precarious Jobs in Labour Market Regulation: The Growth of Atypical Employment in Western Europe; International Institute for Labour Studies: Geneva, Switzerland, 1989.

6. Vosko, L.F.; Zukewich, N.; Cranford, C. Precarious jobs: A new typology of employment. Perspect. Labour Income Ott. 2003, 15, 16-26.

7. Polivka, A.E.; Nardone, T. On the Definition of Contingent Work The Quality of Jobs. Mon. Labor Rev. 1989, 112, 9-16.

8. Quinlan, M.; Bohle, P. Contingent work and occupational safety. In The Psychology of Workplace Safety; Barling, J., Frone, M.R., Eds.; American Psychological Association: Washington, DC, USA, 2004; pp. 81-105.

9. Cummings, K.J.; Kreiss, K. Contingent Workers and Contingent Health: Risks of a Modern Economy. JAMA 2008, 299, 448-450. [CrossRef]

10. Foley, M. Factors underlying observed injury rate differences between temporary workers and permanent peers. Am. J. Ind. Med. 2017, 60, 841-851. [CrossRef]

11. Gibson-Light, M. Classification Struggles in Semi-Formal and Precarious Work: Lessons from Inmate Labor and Cultural Production. In Precarious Work; Emerald Publishing Limited: Bingley, UK, 2017; Volume 31, pp. 61-89. [CrossRef]

12. Kalleberg, A.L.; Vallas, S.P. Probing Precarious Work: Theory, Research, and Politics. In Precarious Work; Emerald Publishing Limited: Bingley, UK, 2017; Volume 31, pp. 1-30. [CrossRef] 
13. Kheni, N.A.; Dainty, A.; Gibb, A. Health and safety management practices of small subcontractors. In Proceedings of the 21st Annual ARCOM Conference, University of London, Association of Researchers in Construction Management, London, UK, 7-9 September 2005.

14. McVittie, D.; Banikin, H.; Brocklebank, W. The effects of firm size on injury frequency in construction. Saf. Sci. 1997, 27, 19-23. [CrossRef]

15. Loosemore, M.; Andonakis, N. Barriers to implementing OHS reforms-The experiences of small subcontractors in the Australian Construction Industry. Int. J. Proj. Manag. 2007, 25, 579-588. [CrossRef]

16. Wong, J.Y.Y.; Gray, J.; Sadiqi, Z. Barriers to good occupational health and safety (OHS) practices by small construction firms. J. Constr. Manag. 2015, 30, 55-66.

17. Milch, V.; Laumann, K. Interorganizational complexity and organizational accident risk: A literature review. Saf. Sci. 2016, 82, 9-17. [CrossRef]

18. Oedewald, P.; Gotcheva, N. Safety culture and subcontractor network governance in a complex safety critical project. Reliab. Eng. Syst. Saf. 2015, 141, 106-114. [CrossRef]

19. Bust, P.D.; Gibb, A.G.F.; Pink, S. Managing construction health and safety: Migrant workers and communicating safety messages. Saf. Sci. 2008, 46, 585-602. [CrossRef]

20. MacKenzie, R. Subcontracting and the reregulation of the employment relationship: A case study from the telecommunications industry. Work Employ. Soc. 2000, 14, 707-726. [CrossRef]

21. Lingard, H.; Holmes, N. Understandings of occupational health and safety risk control in small business construction firms: Barriers to implementing technological controls. Constr. Manag. Econ. 2001, 19, 217-226. [CrossRef]

22. Goldenhar, L.M.; Moran, S.K.; Colligan, M. Health and safety training in a sample of open-shop construction companies. J. Saf. Res. 2001, 32, 237-252. [CrossRef]

23. Luzzia, R.; Maida, L.; Martinettib, A.; Patruccob, M. Information, formation and training for the maintenance operations: The lesson learned from fatal accidents. Chem. Eng. 2013, 32, 229-334.

24. Benavides, F.G.; Benach, J.; Muntaner, C.; Delclos, G.L.; Catot, N.; Amable, M. Associations between temporary employment and occupational injury: What are the mechanisms? Occup. Environ. Med. 2006, 63, 416-421. [CrossRef]

25. Johnstone, R.; Stewart, A. Swimming against the Tide: Australian Labor Regulation and the Fissured Workplace. Comp. Lab. L. Policy J. 2015, 37, 55-90.

26. Vosko, L.F. Precarious Employment: Towards an Improved Understanding of Labour Market Insecurity; McGill-Queen's University Press: Montreal, QC, Canada; Kingston, CA, USA, 2006; Volume 2006.

27. Akintan, O.A.; Morledge, R. Improving the collaboration between main contractors and subcontractors within traditional construction procurement. J. Constr. Eng. 2013, 2013, 281236. [CrossRef]

28. Blackford, J. Can Safety Be Bought in Mining Contracts? The Cobra Effect. Acquire Procurement Services. Available online: http://acquireprocure.com/procurement-insights/can-safety-be-bought-in-mining-servicescontracts-beware-the-cobra-effect/ (accessed on 26 October 2016).

29. Ivensky, V. Safety Risk Management of Subcontractors: What is a standard of care? Prof. Saf. 2008, 53, 43-46.

30. Smith, G.W. Contractor Safety Management; CRC Press: Boca Raton, FL, USA, 2014.

31. Thomas, H.R.; Flynn, C.J. Fundamental Principles of Subcontractor Management. Pract. Period. Struct. Des. Constr. 2011, 16, 106-111. [CrossRef]

32. Hartmann, A.; Ling, F.Y.Y.; Tan, J.S.H. Relative Importance of Subcontractor Selection Criteria: Evidence from Singapore. J. Constr. Eng. Manag. 2009, 135, 826-832. [CrossRef]

33. Wells, J.; Hawkins, J. Promoting Construction Health and Safety Through Procurement: A Briefing Note for Developing Countries; Engineers Against Poverty: London, UK, 2014.

34. Young, B.; Seidu, R.D.; Nganga, D.; Robinson, H.; Ebohon, J.O. Driving Construction Health and Safety through Procurement Strategy; Association of Researchers in Construction Safety, Health, and Well-being (ARCOSH): Cape Town, South Africa. Available online: https://openresearch.lsbu.ac.uk/item/8664x (accessed on 3 June 2019).

35. Miller, C.J.; Packham, G.A.; Thomas, B.C. Harmonization between main contractors and subcontractors: A prerequisite for lean construction? J. Constr. Res. 2002, 3, 67-82. [CrossRef]

36. Dainty, A.R.; Millett, S.J.; Briscoe, G.H. New perspectives on construction supply chain integration. Supply Chain Manag. Int. J. 2001, 6, 163-173. [CrossRef] 
37. Braun, V.; Clarke, V. What can "thematic analysis" offer health and wellbeing researchers? Int. J. Qual. Stud. Health Well-Being 2014, 9, 26152. [CrossRef]

38. Yin, R.K. Case Study Research and Applications: Design and Methods; Sage Publications: New York, NY, USA, 2017.

39. Demichela, M.; Monai, L.; Patrucco, M. The Deep Analysis of the Accidents as an Essential Prevention Tool: A Post-Event Investigation Protocol for the Analyst. In Ingegneria Forense: Metodologie, Protocolli e Casi di Studio; Flaccovio Dario: Palermo, Italy, 2011; pp. 231-246. (In Italian)

40. Martinetti, A.; van Dongen, L.A.M.; Romano, R. Beyond Accidents: A Back-Analysis on Conveyor Belt Injury for a Better Design for Maintenance Operations. Am. J. Appl. Sci. 2017, 14, 1-12. [CrossRef]

41. Dubois, A.; Gadde, L.-E. Systematic combining: An abductive approach to case research. J. Bus. Res. 2002, 55, 553-560. [CrossRef]

42. Nowell, L.S.; Norris, J.M.; White, D.E.; Moules, N.J. Thematic Analysis: Striving to Meet the Trustworthiness Criteria. Int. J. Qual. Methods 2017, 16, 1609406917733847. [CrossRef]

43. Patterson, J. Human Error in Mining: A Multivariable Analysis of Mining Accidents/Incidents in Queensland, Australia and the United States of America Using the Human Factors Analysis and Classification System Framework. Master's Thesis, Clemson University, Clemson, SC, USA, December 2009.

44. Bahn, S. Moving from contractor to owner operator: Impact on safety culture-A case study. Empl. Relat. 2012, 35, 157-172. [CrossRef]

45. Hinze, J.; Gambatese, J. Factors That Influence Safety Performance of Specialty Contractors. J. Constr. Eng. Manag. 2003, 129, 159-164. [CrossRef]

46. Collinson, D.L. 'Surviving the Rigs': Safety and Surveillance on North Sea Oil Installations. Organ. Stud. 1999, 20, 579-600. [CrossRef]

47. Papadopoulos, G.; Georgiadou, P.; Papazoglou, C.; Michaliou, K. Occupational and public health and safety in a changing work environment: An integrated approach for risk assessment and prevention. Saf. Sci. 2010, 48, 943-949. [CrossRef]

48. Quinlan, M. The 'pre-invention'of precarious employment: The changing world of work in context. Econ. Labour Relat. Rev. 2012, 23, 3-24.

49. Lewchuk, W.; Clarke, M.; de Wolff, A. Working without commitments: Precarious employment and health. Work Employ. Soc. 2008, 22, 387-406. [CrossRef]

50. Beard, K.M.; Edwards, J.R. Employees at Risk: Contingent Work and the Psychological Experience of Contingent Workers. J. Organ. Behav. 1995, 2, 109.

51. Virtanen, M.; Kivimäki, M.; Joensuu, M.; Virtanen, P.; Elovainio, M.; Vahtera, J. Temporary employment and health: A review. Int. J. Epidemiol. 2005, 34, 610-622. [CrossRef] [PubMed]

52. Lingard, H.; Rowlinson, S.M. Occupational Health and Safety in Construction Project Management; Spon Press: New York, NY, USA, 2005.

53. Bentley, T.; Tappin, D.; Legg, S. An exploratory analysis of falls in New Zealand small business residential construction. J. Occup. Health Saf. Aust. N. Z. 2004, 20, 539-545.

54. Bahn, S. Workplace hazard identification and management: The case of an underground mining operation. Saf. Sci. 2013, 57, 129-137. [CrossRef]

55. Bahn, S.; Barratt-Pugh, L. Evaluation of the mandatory construction induction training program in Western Australia: Unanticipated consequences. Eval. Program Plan. 2012, 35, 337-343. [CrossRef] [PubMed]

56. Kaskutas, V.; Jaegers, L.; Dale, A.M.; Evanoff, B. Toolbox talks: Insights for improvement. Prof. Saf. 2016, 61, 33-37.

57. Olson, R.; Varga, A.; Cannon, A.; Jones, J.; Gilbert-Jones, I.; Zoller, E. Toolbox talks to prevent construction fatalities: Empirical development and evaluation. Saf. Sci. 2016, 86, 122-131. [CrossRef]

58. ICAO. Safety Management Manual (SMM), 3rd ed.; International Civil Aviation Organization: Montreal, QC, Canada, 2013. Available online: https://www.skybrary.aero/bookshelf/books/644.pdf (accessed on 21 May 2020).

59. Rowlinson, S.M. Construction Safety Management Systems, 1st ed.; Spon Press: London, UK, 2004.

60. Choudhry, R.M.; Dongping, F.; Ahmed, S.M. Safety Management in Construction: Best Practices in Hong Kong. J. Prof. Issues Eng. Educ. Pract. 2008, 134, 20-32. [CrossRef] 
61. Gallagher, C.; Underhill, E.; Rimmer, M. Occupational Health and Safety Management Systems: A Review of Their Effectiveness in Securing Healthy and Safe Workplaces [Review]; National Occupational Health and Safety Commission: Sydney, Australia, 2001; pp. 1-82. Available online: https://www.safeworkaustralia.gov.au/ system/files/documents/1702/ohsmanagementsystems_reviewofeffectiveness_nohsc_2001_archivepdf.pdf (accessed on 13 May 2020).

62. Masi, D.; Cagno, E.; Micheli, G.J. Developing, implementing and evaluating OSH interventions in SMEs: A pilot, exploratory study. Int. J. Occup. Saf. Ergon. 2014, 20, 385-405. [CrossRef] [PubMed]

63. Segarra Cañamares, M.; Villena Escribano, B.M.; González García, M.N.; Romero Barriuso, A.; Rodríguez Sáiz, A. Occupational risk-prevention diagnosis: A study of construction SMEs in Spain. Saf. Sci. 2017, 92, 104-115. [CrossRef]

64. Quinlan, M.; Johnstone, R.; McNamara, M. Australian Health and Safety Inspectors' Perceptions and Actions in Relation to Changed Work Arrangements. J. Ind. Relat. 2009, 51, 557-573. [CrossRef]

65. Boiral, O.; Ebrahimi, M.; Kuyken, K.; Talbot, D. Greening remote SMEs: The case of small regional airports. J. Bus. Ethics 2019, 154, 813-827. [CrossRef]

66. Spence, L.J. Does size matter? The state of the art in small business ethics. Bus. Ethics A Eur. Rev. 1999, 8 , 163-174. [CrossRef]

67. Wadick, P. Safety culture among subcontractors in the domestic housing construction industry. Struct. Surv. 2010, 28, 108-120. [CrossRef]

(C) 2020 by the authors. Licensee MDPI, Basel, Switzerland. This article is an open access article distributed under the terms and conditions of the Creative Commons Attribution (CC BY) license (http://creativecommons.org/licenses/by/4.0/). 